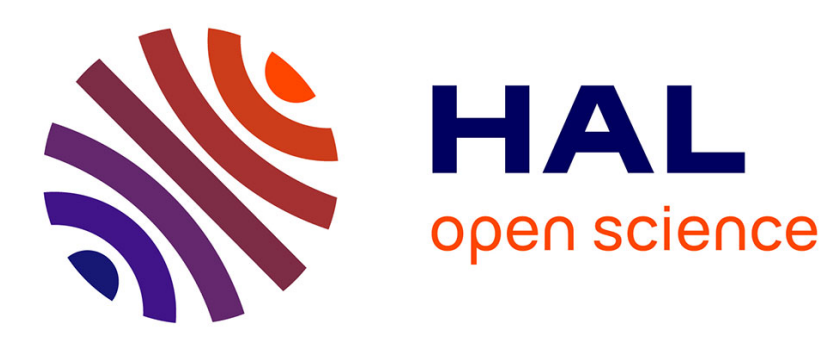

\title{
UTERINE SMOOTH MUSCLE CELL FORCE GENERATION FROM ELECTRICAL PROPERTIES
}

M Yochum, J Laforêt, C Marque

\section{To cite this version:}

M Yochum, J Laforêt, C Marque. UTERINE SMOOTH MUSCLE CELL FORCE GENERATION FROM ELECTRICAL PROPERTIES. International Conference on Clinical and BioEngineering for Women's Health - BioMedWomen 2015, Jun 2015, Porto, Portugal. hal-01328491

\section{HAL Id: hal-01328491 https://hal.science/hal-01328491}

Submitted on 10 Jun 2016

HAL is a multi-disciplinary open access archive for the deposit and dissemination of scientific research documents, whether they are published or not. The documents may come from teaching and research institutions in France or abroad, or from public or private research centers.
L'archive ouverte pluridisciplinaire HAL, est destinée au dépôt et à la diffusion de documents scientifiques de niveau recherche, publiés ou non, émanant des établissements d'enseignement et de recherche français ou étrangers, des laboratoires publics ou privés. 
BioMedWomen - International Conference on Clinical and BioEngineering for Women's Health

Porto, Portugal, 20 - 23 June 2015

\title{
UTERINE SMOOTH MUSCLE CELL FORCE GENERATION FROM ELECTRICAL PROPERTIES
}

\author{
M. Yochum, J. Laforêt and C. Marque
}

Sorbonne University, Université de technologie de Compiègne, CNRS,UMR 7338 Biomechanics and Bioengineering, Centre de recherche Royallieu -CS 60319- 60203 Compiègne cedex, France

KEYWORDS: Uterine smooth muscle modelling, Biomedical, electrical-force coupling

\begin{abstract}
In this study, we propose the coupling of two different model of uterine smooth muscle cell. One is an electrical model an the other is a mechanical model. The coupling between both models is based on the concentration of calcium inside the cell compartment. Two results are shown, one is a result for a unique cell with one and several action potentials induced, the other is for a two dimensional tissue like matrix. Results show that when several action potentials are initiated in the electrical model, the tissue is able to contract entirely.

Introduction: The electromyogram recording of the uterine muscle is a useful technique to get a clinical diagnosis over the women's pregnancy. In that condition, the EMG is named electrohysterogram (EHG) [1]. This EHG gives information only about the electrical activity of the muscle, which is a very important component of the contraction. This muscular electrical activity pass through different kind of tissues, including fat and skin, and then undergoes a spatial and frequency filtering before being recorded with electrodes. A correlation between the electrical activity model of uterine cell and the EHG has already been proved [2]. However, EHG does not give information about the mechanical effect on the smooth muscle cells (SMC), such as the force generation. The knowledge of this force of each cell of the uterine muscle could, for instance, lead to the computation of the intrauterine pressure which is another measure that physician can performed to evaluate the uterus working [3]. It is obvious that the electrical and the mechanical properties of this smooth muscle are linked together. It is widely admit that the contraction of SMCs are initiated by the intracellular calcium concentration, named $\left[\mathrm{Ca}^{2+}\right] \mathrm{i}$, which links itself to the contractile elements of the SMC (actin and myosin) [4]. It is also proved that the mechanical changes in the SMC induce electrical modification of the cell, especially though stretch-activated channels [5]. The latter is not considered in the study proposed here.

Purpose: We proposed here a modelization of the uterine smooth muscle with an electrical-force coupled model where the electrical aspects of the contraction are correlated with the force generation. In this way, the electrical propagation through the muscle can be used to observe mechanical force which is produced. In addition, the electrical
\end{abstract}


properties of the SMCs do not seam sufficient enough to justify the contraction behavior of the SMCs because the dynamics of SMCs contraction are slower than electrical ones. Indeed, even when an action potential (AP) cycle of a cell is over, the cell continue being contracted. A Such model could be used to correlate the electrical activity of the muscle, which is easily recorded with EHG signals, with the force generation of the muscle. This could lead to a better determination for predicting and preventing pre-term labor for instance.

Materials and Methods: To obtain the developed force of a SMC, we used a modified Hai-Murphy model (from a the original model of Hai-Murphy [6] which was originally made for the airway SMCs) which is dedicated to the uterine muscle [7]. This model has been chosen because it is commonly used to determine the force generation of SMCs $[8,9,10]$ and it was correlated with experimental measurement, in particular for uterine muscle $[7,11]$ which is the targeted muscle in this study. Hai-Murphy model is coupled with an electrical model from a previous study [2] which include the intracellular concentration of calcium ions. The coupling is then performed with this calcium concentration which is an important parameter in the modified Hai-Murphy force model. We first introduce the electrical model of the uterine SMC and next the mechanical model.

Electrical model: The Red3 model (Reduced 3 equations) is used here. It is a reduced version of the model from [12], based on Hodgkin-Huxley model, express such as:

$$
\begin{gathered}
\frac{d V_{m}}{d t}=\frac{1}{C_{m}}\left(I_{s t i m}-I_{C a}-I_{K}-I_{K C a}-I_{l e a k}\right), \quad \frac{d n_{K}}{d t}=\frac{h_{K_{\infty}}-n_{K}}{\tau_{n_{K}}}, \\
\frac{d\left[C a^{2+}\right]}{d t}=f_{c}\left(-\alpha I_{C a}-K_{C a}\left[C a^{2+}\right]\right),
\end{gathered}
$$

where $V_{m}$ the trans-membrane potential, $n_{K}$ the potassium activation variable, and $\left[\mathrm{Ca}^{2+}\right] i$ the intracellular calcium concentration. Other information about this model can be found in [2]. The link between SMCs is modeled through gap-junctions with a spacial diffusion of $V_{m}$ over the cells. This model has the particularity to compute the intracellular calcium concentration which allows the link with the mechanical model below. That is not always the case in AP models as FitzHugh-Nagumo or Noble models for instance.

Mechanical model: We use for this study, the modified Hai-Murphy model from Maggio et al [7] who modified the original model [6] to better correspond to uterine SMCs. The mechanical contraction is based on four-state kinetic cross-bridge where the fraction of cross-bridge in each state can be computed. The figure 1 shows a diagram of the four states cross-bridges denoted $\mathrm{M}$ for unattached and unphosphorylated, Mp for unattached and phosphorylated, AMp for attached and phosphorylated, and AM for attached and unphosphorylated. $\mathrm{k} 1$ to $\mathrm{k} 7$ are the transition rates from one state to another where $\mathrm{k} 1$ and $\mathrm{k} 6$ are the myosin head phosphorylation rate, $\mathrm{k} 2$ and $\mathrm{k} 5$ are the dephosphorylation rate, $\mathrm{k} 3$ is the myosin head attachment rate, and $\mathrm{k} 4$ and $\mathrm{k} 7$ are the myosin head detachment. From the reference [7], $\mathrm{k} 1=\mathrm{k} 6$ and $\mathrm{k} 2=\mathrm{k} 5$ and the equations of cross-bridges distribution are:

$$
\left(\begin{array}{c}
d M / d t \\
d M p / d t \\
d A M p / d t \\
d A M / d t
\end{array}\right)=\left(\begin{array}{cccc}
-k 1 & k 2 & 0 & k 7 \\
k 1 & -k 2-k 3 & k 4 & 0 \\
0 & k 3 & -k 4-k 5 & k 6 \\
0 & 0 & k 5 & -k 6-k 7
\end{array}\right)\left(\begin{array}{c}
M \\
M p \\
A M p \\
A M
\end{array}\right)
$$

where the initial conditions are $\mathrm{M}(0)=1$ and $\operatorname{Mp}(0)=\operatorname{AMp}(0)=\operatorname{AM}(0)=0$ and the sum of the four states is always one. The link between the two models is based on the calcium 
concentration and how this concentration acts on the mechanical model. The link has been introduced by Burzstyn et al. [11] on the $\mathrm{k} 1$ parameter (the phosphorylated rate of cross-bridges):

$$
k 1(t)=\frac{\left[C a^{2+}\right]_{i}^{n_{M}}}{\left[C a^{2+}\right]_{i}^{n_{M}}+\left[C a_{1 / 2 M L C K}^{2+}\right]^{n_{M}}},
$$

$$
F(t)=K(A M p(t)+A M(t))
$$

where $\left[\mathrm{Ca}_{1 / 2 M L C K}^{2+}\right]$ is the concentration of intracellular calcium which corresponds to half activation of the myosin light-chain kinase and $n_{M}$ is the Hill coefficient of that activation. Then, the force generated by the SMC is the sum of both attached state (AM and AMp) with a proportional coefficient $K$ (equation 4 ).

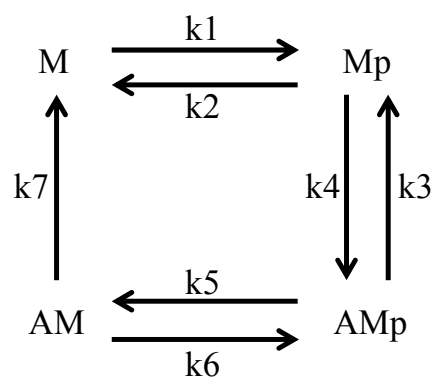

Figure 1: Diagram of the cross-bridge cycle of Hai-Murphy model. M means unattached and unphosphorylated, Mp means unattached and phosphorylated, AMp means attached and phosphorylated, AM means attached and unphosphorylated. $\mathrm{k} 1$ to $\mathrm{k} 7$ are the transition rates from one state to another.
Table 1: Parameters of the mechanical HaiMurphy model from Maggio et al. experiment $[7]$

\begin{tabular}{ll}
\hline \hline Parameter & Value \\
\hline$\left[C a_{1 / 2 M L C K}^{2+}\right]$ & $464.0758 \mathrm{nM}$ \\
$\mathrm{k} 2$ & $0.1399 \mathrm{~s}^{-1}$ \\
$\mathrm{k} 3$ & $14.4496 \mathrm{~s}^{-1}$ \\
$\mathrm{k} 4$ & $3.6124 \mathrm{~s}^{-1}$ \\
$\mathrm{k} 5$ & $\mathrm{k} 2$ \\
$\mathrm{k} 6$ & $\mathrm{k} 1$ \\
$\mathrm{k} 7$ & $0.1340 \mathrm{~s}^{-1}$ \\
$\mathrm{n}_{\mathrm{M}}$ & 4.7135 \\
$\mathrm{~K}$ & 5.0859 \\
\hline
\end{tabular}

Results: When an AP is initiated in the electrical model, that induces an increase of the calcium concentration in the cell [2]. The calcium lies itself with the calmoduline which activates the actin-myosin sliding with one another, and then, produce a force generation. The result of the force is given at two different scales: with a unique cell and with a tissue like matrix of cells.

One cell: In the figure 2, an example of the co-simulation of both electrical and mechanical model is presented. A unique AP was induced in the electrical model with a stimulation current added to Vm. we see that the AP triggers an increase in the calcium concentration. Then, the force start to increase and stays activated even when the calcium concentration becomes low. That is due to the mechanical dynamics which is slower than electrical one. In the figure 3, we see an example of both model working together with a continuous stimulation which allows the generation of AP in series. In that way, we see on the panel a. the Vm potential where 20 APs are generated over 15 seconds. The influence of the successive APs, on the mechanical model, is that their is an accumulation of the generated force from each AP. Indeed, in the panel c. we see the generate force being higher and higher through APs. This phenomenon is due to the calcium concentration which is longer present in the 
cell at a high value which let more time to the mechanical process to be activated. With continuous AP fire, the mechanical model reacts as if the cell was in a tetanic contraction.
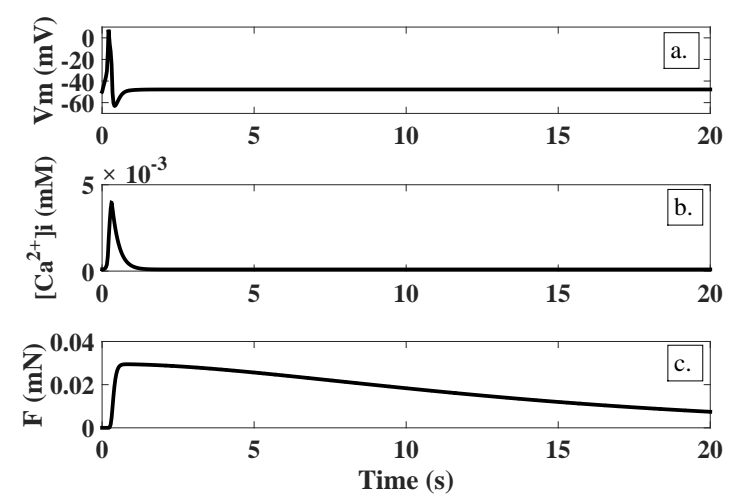

Figure 2: Example of the coupling of both electrical and mechanical models where one twitch was induced. We see in a. the inter-membrane tension $\mathrm{Vm}$ and in b. the calcium concentration from the electrical model. In c, we see the force generation from the mechanical model and the link with calcium concentration from the electrical model.
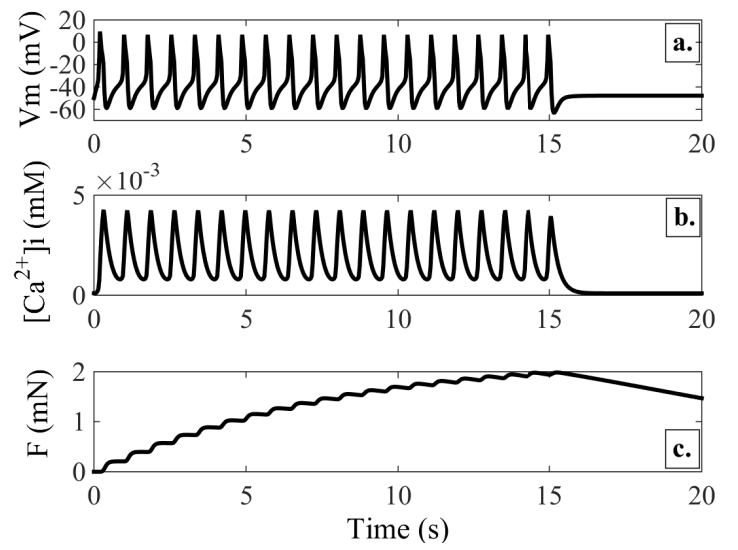

Figure 3: Example of the coupling of both electrical and mechanical models where several APs were induced during 15 seconds. We see in a. the intermembrane tension $\mathrm{Vm}$ and in $\mathrm{b}$. the calcium concentration from the electrical model. In c., we see the force generation from the mechanical model and the link with calcium concentration from the electrical model.

Tissue like matrix of cells: In the figures 4 and 5, an example of the co-simulation of both electrical and mechanical model is presented for a two dimensional tissue with 150 by 150 SMCs. A peacemaker cell is controlled at the center of the tissue $([125 ; 125])$. In the figure 4 we see the electrical properties of the tissue through the potentials $\mathrm{Vm}$. To the top, the temporal inter-membrane potential Vm signal of the cell (position: $[10 ; 10]$ ). To the bottom, six pictures of the two dimensional Vm view (corresponding to time $t=\{0.1$, $0.45,0.85,1.25,1.65,2.05 \mathrm{~s}\}$ ) where we see the APs spread along the tissue. In the figure 5 we see the mechanical properties of the tissue through the force F. To the top, the temporal force $\mathrm{F}$ signal of the cell (position: $[10 ; 10])$. To the bottom, six pictures of the two dimensional force view (corresponding to time $t=\{0,2,4,6,8,10 \mathrm{~s}\}$ ) where we see the SMCs being contracted on the entire tissue. We can notice that the Vm potentials (issue from the APs spreading along the tissue, see figure 4) are not at the same value on the entire tissue at a $t$ instant. This is not the case for the force values (see figure 5) which are quite similar along the tissue, certainly due to the slower dynamics of the mechanical model. This behavior is quite similar to the uterine working in the sense that, when observing an EHG, a lot of APs are recorded while a unique twitch of force is recorded over one contraction through intrauterine pressure [13]. A video of this simulation is available online at: http://www.utc.fr/ webdsi/mesdocuments/data/public/ 86f8e9b5a20c75a8bc6569b765aa89d1.php

Discussion and Conclusions: In this work, we saw a possible combination of two models giving a relation between electrical AP propagation and the force generation of the 

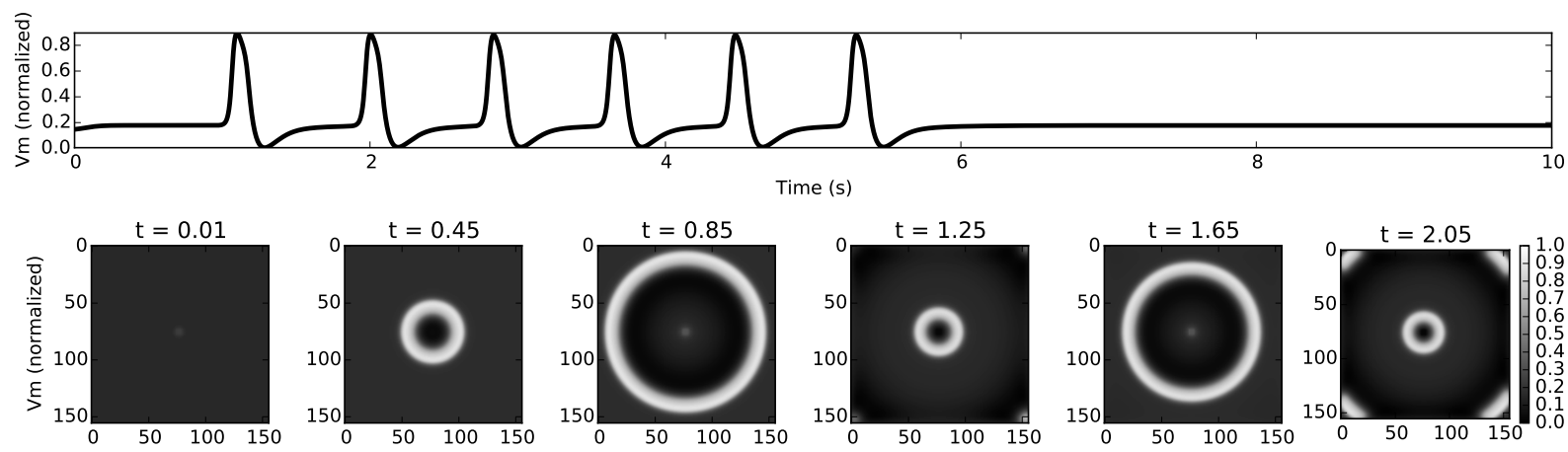

Figure 4: Example of Vm for a co-simulation with two dimensional tissue. To the top, the temporal signal of the cell (position: $[10 ; 10]$ ) inter-membrane potential Vm. To the bottom, six pictures of the two dimensional Vm view where we see the APs spread along the tissue.
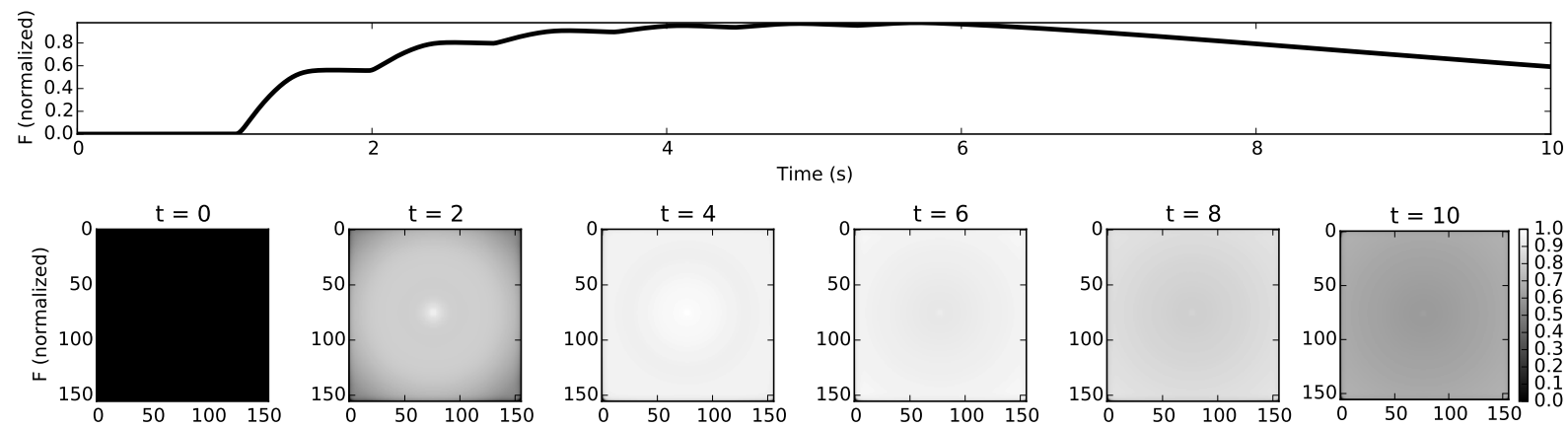

Figure 5: Example of Force for a co-simulation with two dimensional tissue. To the top, the temporal signal of the cell (position: $[10 ; 10]$ ) force F. To the bottom, six pictures of the two dimensional force view where we see the SMCs being contracted on the entire tissue.

uterine SMCs. Results show the dependence of the force generation from the electrical AP propagation through the muscular tissue. However, a kind of inertia of the force, with respect to the AP, is present, which maintain a force generation during the cells repolarization. That could be due to the strong dephosphorylated attached myosin. The correlation between electrical and mechanical model could lead to a better understanding of mechanisms over the uterine contraction. For instance, link the entire uterine muscle contraction with force and electrical cells properties together could lead to a prediction of the contraction under divers constrains (medicinal for instance). A future study will be to use the result of the force computation with the deformation of the muscle cell and the distortion of shape which can exist among cells.

Acknowledgment: This work was carried out and funded in the framework of the Labex MS2T. It was supported by the French Government, through the program "Investments for the future managed by the National Agency for Research (Reference ANR-11-IDEX0004-02) 


\section{REFERENCES}

[1] Devedeux D, Marque C, Mansour S, Germain G, Duchêne J. Uterine electromyography: a critical review. American journal of obstetrics and gynecology. 1993;169(6):1636-1653.

[2] Laforet J, Rabotti C, Terrien J, Mischi M, Marque C. Toward a multiscale model of the uterine electrical activity. IEEE Transactions on Biomedical Engineering. 2011;58(12):3487-3490.

[3] Bastos LF, Lobo MF, van Meurs WL, Ayres-de Campos D. An intrauterine pressure generator for educational simulation of labour and delivery. Medical engineering \& physics. 2010;32(7):740-745.

[4] Webb RC. Smooth muscle contraction and relaxation. Advances in physiology education. 2003;27(4):201-206.

[5] Guibert C, Ducret T, Savineau JP. Voltage-independent calcium influx in smooth muscle. Progress in biophysics and molecular biology. 2008;98(1):10-23.

[6] Hai CM, Murphy RA. Cross-bridge phosphorylation and regulation of latch state in smooth muscle. American Journal of Physiology-Cell Physiology. 1988;254(1):C99 C106.

[7] Maggio CD, Jennings SR, Robichaux JL, Stapor PC, Hyman JM. A modified Hai Murphy model of uterine smooth muscle contraction. Bulletin of mathematical biology. 2012;74(1):143-158.

[8] Wang I, Politi AZ, Tania N, Bai Y, Sanderson MJ, Sneyd J. A mathematical model of airway and pulmonary arteriole smooth muscle. Biophysical journal. 2008;94(6):20532064.

[9] Hai CM, Kim HR. An expanded latch-bridge model of protein kinase C-mediated smooth muscle contraction. Journal of applied physiology. 2005;98(4):1356-1365.

[10] Yang J, Clark JW, Bryan RM, Robertson C. The myogenic response in isolated rat cerebrovascular arteries: smooth muscle cell model. Medical engineering \& physics. 2003;25(8):691-709.

[11] Bursztyn L, Eytan O, Jaffa AJ, Elad D. Mathematical model of excitationcontraction in a uterine smooth muscle cell. American Journal of Physiology-Cell Physiology. 2007;292(5):C1816-C1829.

[12] Rihana S, Terrien J, Germain G, Marque C. Mathematical modeling of electrical activity of uterine muscle cells. Medical \& biological engineering \& computing. 2009;47(6):665-675.

[13] Garfield RE, Maner WL. Physiology and electrical activity of uterine contractions. In: Seminars in cell \& developmental biology. vol. 18. Elsevier; 2007. p. 289-295. 